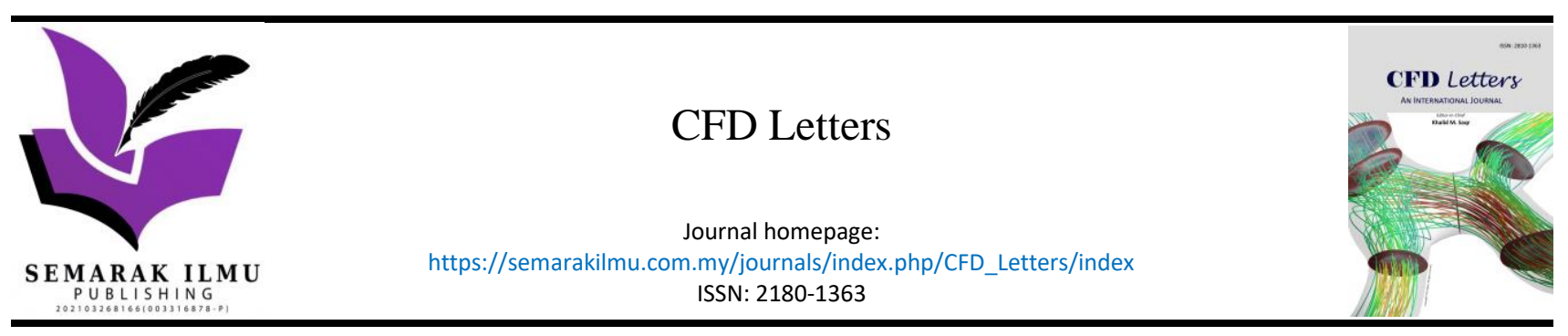

\title{
A Validation Study of the Aerodynamic Behaviour of a Wind Turbine: Three-Dimensional Rotational Case
}

\author{
Khaoula Qaissi ${ }^{1, *}$, Omer Elsayed ${ }^{1}$, Mustapha Faqir $^{1}$, Elhachmi Essadiqi ${ }^{1}$ \\ 1 Université Internationale de Rabat, School of aerospace and automotive engineering, LERMA Lab, Campus UIR Parc Technopolis, Rocade, Rabat- \\ Sale, 11100 - Sala Al Jadida, Maroc, Morocco
}

ARTICLE INFO

\section{Article history:}

Received 15 August 2021

Received in revised form 1 September 2021

Accepted 3 September 2021

Available online 8 September 2021

\section{Keywords:}

NREL phase VI; wind turbine; CFD; Komega SST; Flow Separation

\section{ABSTRACT}

Numerical modelling and simulation of a rotating, tapered, and twisted threedimensional blade with turbulent inflow conditions and separating flows is a challenging case in Computational Fluid Dynamics (CFD). The numerical simulation of the fluid flow behaviour over a wind turbine blade is important for the design of efficient machines. This paper presents a numerical validation study using the experimental data collected by the National Renewable Energy Laboratory (NREL). All the simulations are performed on the sequence $S$ of the extensive experimental sequences conducted at the NASA/Ames wind tunnel with constant RPM and variable wind speeds. The results show close agreement with the NREL UAE experimental data. The CFD model captures closely the totality of the defining quantities. The shaft torque is well-predicted pre-stall but under-predicted in the stall region. The threedimensional flow and stall are well captured and demonstrated in this paper. Results show attached flow in the pre-stall region. The separation appears at a wind speed of $10 \mathrm{~m} / \mathrm{s}$ near the blade root. For $\mathrm{V}>10 \mathrm{~m} / \mathrm{s}$, the blade appears to experience a deep stall from root to tip.

\section{Introduction}

A wind turbine rotating blade is a complicated three-dimensional shape that encompasses twodimensional airfoils with a specific setup to optimize the output power generation. With the development in computational tools and powers, there has been a growing body of research to increase the predictive power of wind turbine simulations. The latter will allow accelerating the process of testing new blade designs. This is important to accompany the current development in the wind turbine industry, aiming to relocate offshore where higher winds are more common[1-3].

In April 2000 The National Renewable Energy Laboratory conducted an Unsteady Aerodynamics Experiment (UAE) in the NASA Ames $24.4 \mathrm{~m} \times 36.6 \mathrm{~m}$ wind tunnel [4] shown in Figure 1. The NREL phase $\mathrm{VI}$ wind turbine presents excellent validation cases for CFD. The extensive experimental campaign resulted in extensive and inclusive data printed in various NREL reports [4-7]. In this paper,

\footnotetext{
* Corresponding author.

E-mail address: khaoula.qaissi@uir.ac.ma (Khaoula Qaissi)
} 
sequence $S$ is adopted and compared with the measurements available from a three-week experimental campaign.

Since the NREL phase VI wind turbine is in an upwind configuration, the effect of the nacelle and the tower can be neglected for CFD calculations. In literature, only a handful of researchers opted for a full wind turbine in CFD simulation [8-10], because of the added cost for additional resources and the perks of the interaction between objects in relative motions. Fluid-structure interaction (FSI) studies $[11,12]$ showed that the presence of the nacelle and tower gives a minor difference compared to the case of the blades alone. A sliding interface is used in this paper and generally applied in literature, to address the effect of the full rotating wind turbine.

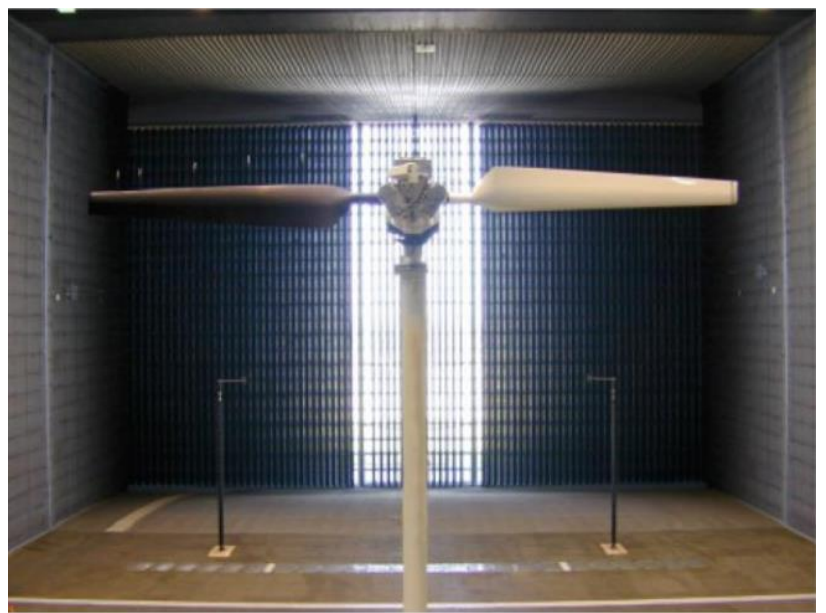

(a)

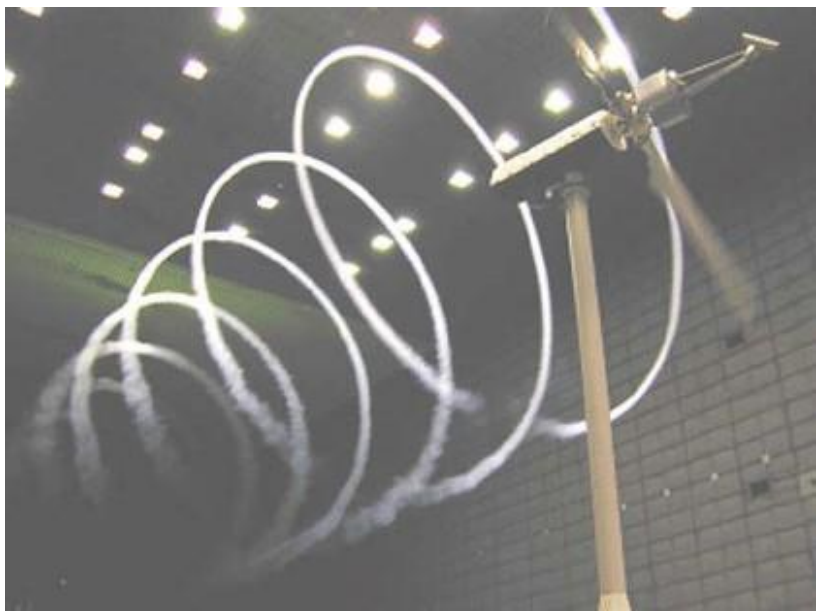

(b)

Fig. 1. NREL Phase VI Rotor in the NASA Ames stationary (a) and rotating (b) sequence $S$ wind turbine [6]

The extensive measurements were studied by different computational researchers using a variety of computational methods and grid topologies [7,13-16]. In recent years, many efforts have been directed towards raising the fidelity of numerical modeling in predicting the complex flow behavior around wind turbines. In the presence of computational resources for finely structured mesh topologies, the obtained results are significantly comparable to the experimental results. Aksenov et al., [17] compared results for different low computational resource scenarios and showed that the k$\omega$ Shear Stress Transport turbulence model (SST) shows close agreement to the experimental results for limited resource scenarios.

Investigating the flow behavior over the three-dimensional rotating wind turbine is a necessary step in a blade optimization process. The rotating blade displays phenomena due to the threedimensional fluid flow that influences the aerodynamics loads [18]. The aerodynamics characteristics of the cross-section profile are different from that of the three-dimensional case. For instance, the separation point is shifted and the coefficient of lift increases for most of the typical cases. Many researchers have investigated aerodynamic loads improvement on two-dimensional wind turbine thick airfoils [19-22], the effectiveness of the flow control, investigated for the two-dimensional profiles, is questionable for a three-dimensional rotating blade. In order to compare the performance of a wind turbine with control to existing experimental data, this validation will allow creating a baseline for further improvement assessment.

A large amount of flow control strategies have been introduced for aerodynamic improvements of rotor blades in the wind industry [23]. The implementation and success of these flow control techniques are directly connected to the aerodynamic behavior of the machine [24]. For instance, some active and passive flow control techniques aim to delay separation and reduce the wake, which requires a preliminary study of the flow behavior over the machine, especially for wind turbines, 
known for their unsteady aerodynamics. The importance of this research work lies in predicting aerodynamic loads on a full-scale wind turbine and the ability to efficiently predict the behavior and efficiency of future design through computational methods. This paper presents a validation study and uses low-cost computational resources in predicting the aerodynamic characteristics of the flow around the NREL phase VI wind turbine. In this paper, an unstructured grid is used with the k- $\omega$ SST model to assess the ability of numerical software to accurately predict the different aerodynamic properties of a rotating blade. This study also presents a quantitative evaluation of the flow separation areas over a three-dimensional rotating wind turbine blade. The aerodynamic properties of the three-dimensional blade were further discussed as a baseline for future flow control considerations to improve the overall wind turbine efficiency.

\section{Rotor Blade Specifications and Mesh}

As mentioned above, a single blade is modeled for all the current simulations. The computational model is reduced to one blade, in order to decrease the required power and resources for the numerical simulation. The effect of the second blade is accounted for using periodic boundary conditions with a rotation of $180^{\circ}$. The blade geometry, shown in Figure 2 , is based on the twisted and tapered extended geometry of the NREL phase VI wind turbine. The detailed specifications of the geometry are expressed in detail in the available literature [25].

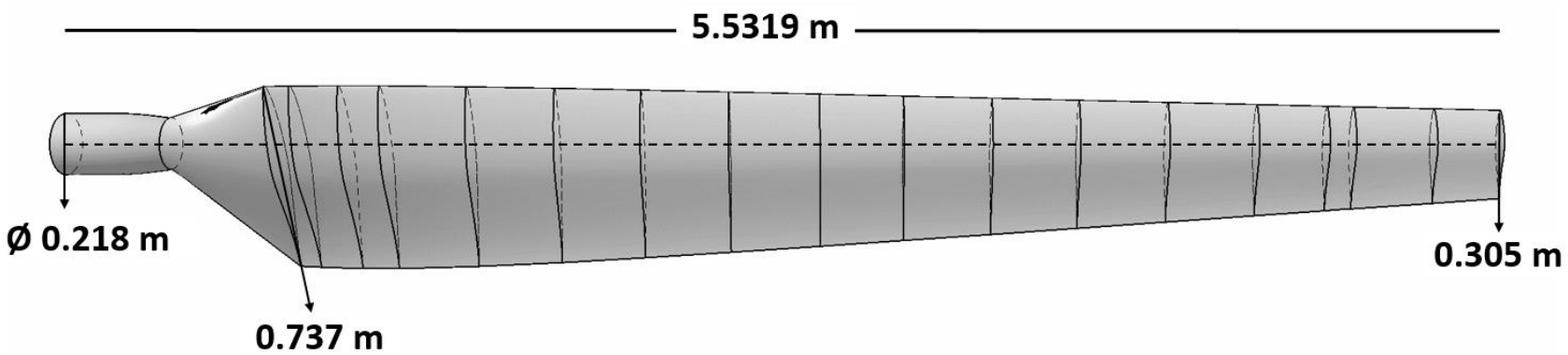

Fig. 2. Blade geometry and mesh

Different researchers promote the use of a blunt edge in order to smoothen the generated mesh. In this work, the original sharp edge is maintained as per Chao and Van Dam's [26] report on possible discrepancies due to the use of a blunt edge.

The cross-section profile is the NREL S809 thick airfoil. In reference [25], the first airfoil is set at $25 \%$ of the total blade radius. There is a lack of information about the exact geometry of the transition part between the cylinder at $17.6 \%$ of the blade span and the first known airfoil. In the model shown in Figure 2, this part of the extended blade is automatically generated by a commercial CAD (Computer-Aided Design) program.

The domain, shown in Figure 3, is a half-cylinder of radius 10 times the radius $\mathrm{R}$ of the blade. The base contains two-periodic surfaces, separated by an angle of $180^{\circ}$. The inlet is set at a distance equal to $10 \mathrm{R}$ and the outlet is $20 \mathrm{R}$ away from the blade position. These specifications are capable of capturing the flow around the wind turbine rotor blade without interfering with it or generating any reverse flow. 


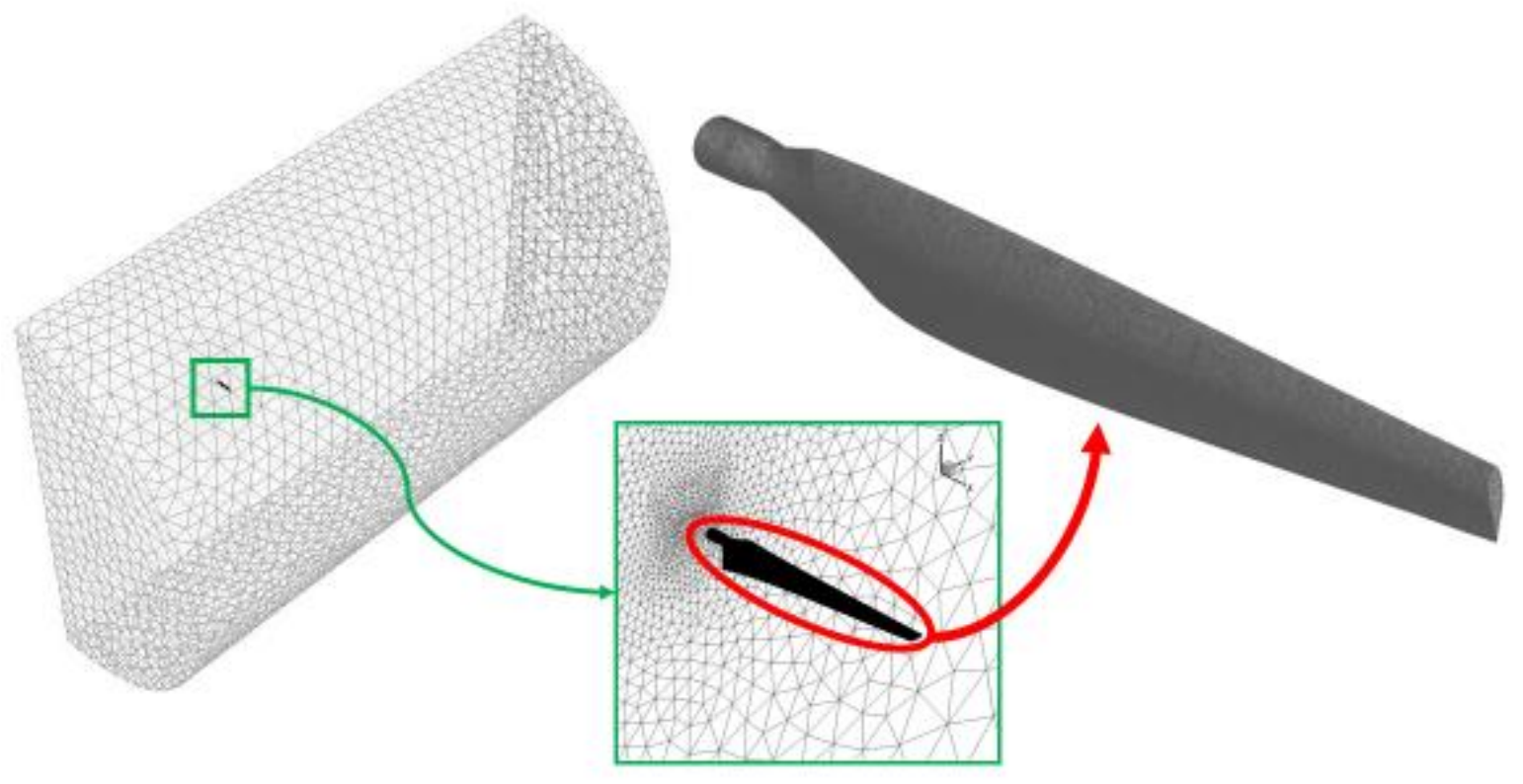

Fig. 3. Triangular Unstructured mesh on the domain and the blade

Fully unstructured triangular mesh is used throughout the computations for the complex tapered and twisted geometry of the blade. The mesh is built on the ANSYS mesh tool. The mesh is highly clustered around the blade and becomes coarser towards the domain external edges. In order to avoid the effect of the near-wall function, the mesh is refined in the wall-normal direction extremely close to the blade surface [27]. Details of the generated mesh are presented in Table 1.

Table 1

Mesh parameters details

\begin{tabular}{ll}
\hline Parameters & \\
\hline Volume mesh & Tetrahedral \\
Total number of elements & 2739225 \\
Total number of nodes & 488122 \\
Inflation option & First Layer thickness \\
Growth rate & 1.1 \\
Number of layers & 20 \\
First layer thickness $(\mathrm{m})$ & 5 e-3 \\
\hline
\end{tabular}

For all the presented simulations in this work, a rotating domain and stationary blade is adopted. The no-slip boundary condition is used over the blade surface. The velocity is fixed at the inlet, where a standard inlet condition is given, and a zero gradient boundary condition is specified at the outlet. The computations were carried out using coupled velocity/pressure equation and second-order discretization.

A grid independence study, in Figure 4, is undertaken in order to ensure that the results obtained with the CFD code are independent of the input mesh resolution. This refinement study is conducted on wind speeds of $7 \mathrm{~m} / \mathrm{s}$ and $10 \mathrm{~m} / \mathrm{s}$ to ascertain whether the selected grid density had sufficient resolution to accurately describe the flow. The coarser mesh is made of 1.45 million grid elements and the finer mesh is composed of 4 million grid elements. With a mean shaft torque value of 413 N.m, the four computations have shown a mean deviation of no greater than $3.4 \%$. This indicates that the solution reached with the selected mesh is independent of the grid resolution. It is safe to 
state that the used mesh allows close prediction of the experimental shaft torque without influencing the results.

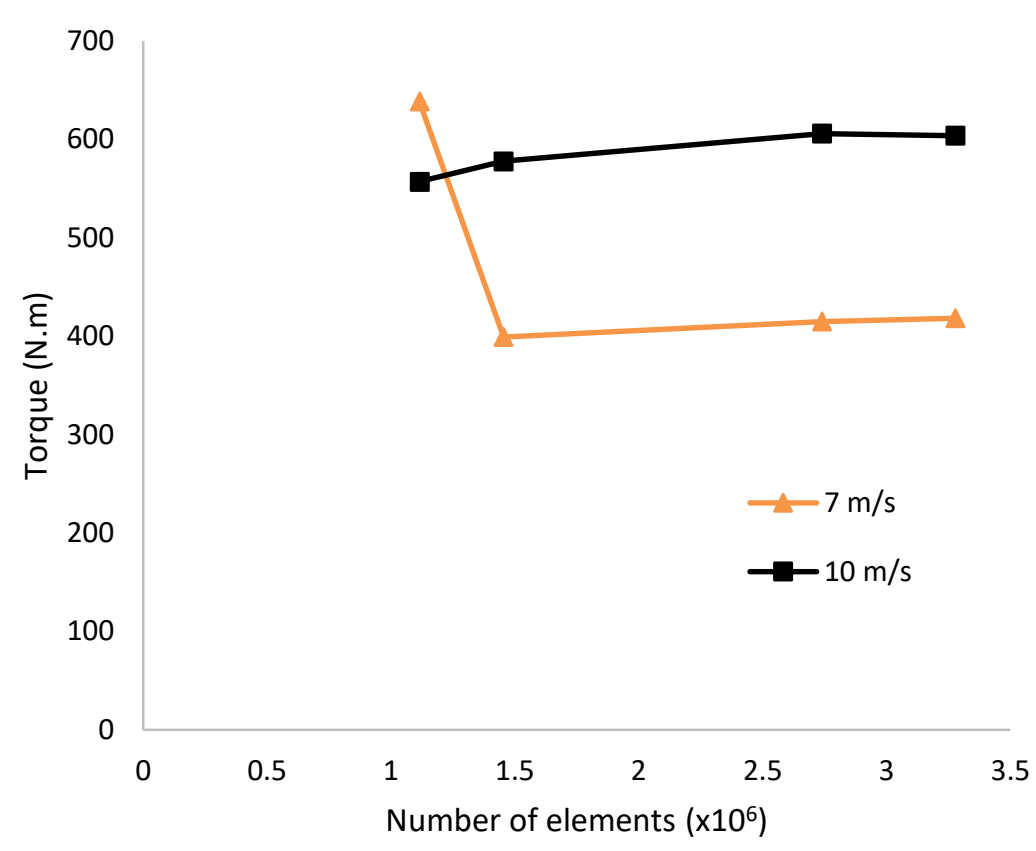

Fig. 4. Grid independence study with different mesh topologies

\section{Methodology}

The current study uses the CFD commercial software ANSYS inc, which is based on a cell-centered finite volume method. The Shear Stress Transport $k-\omega$ turbulence model is used to perform computation on the NREL phase VI Sequence $S$ case, with constant RPM and variable wind speeds. To capture the contribution of the second blade, periodic rotating interfaces are used with a rotation of $180^{\circ}$.

\subsection{Analysis Conditions}

For the numerical simulations conducted in this paper, the pressure-velocity coupling is obtained using the SIMPLE algorithm and second-order upwind schemes are used for pressure, momentum, and turbulence solving equations. The steady state computations were performed for an error of less than $0.001 \%$ for all the relevant variables, and convergence is attained for 500 iterations. A sample of the residuals obtained for a wind speed of $10 \mathrm{~m} / \mathrm{s}$ demonstrates the convergence of the results is shown in Figure 5. 


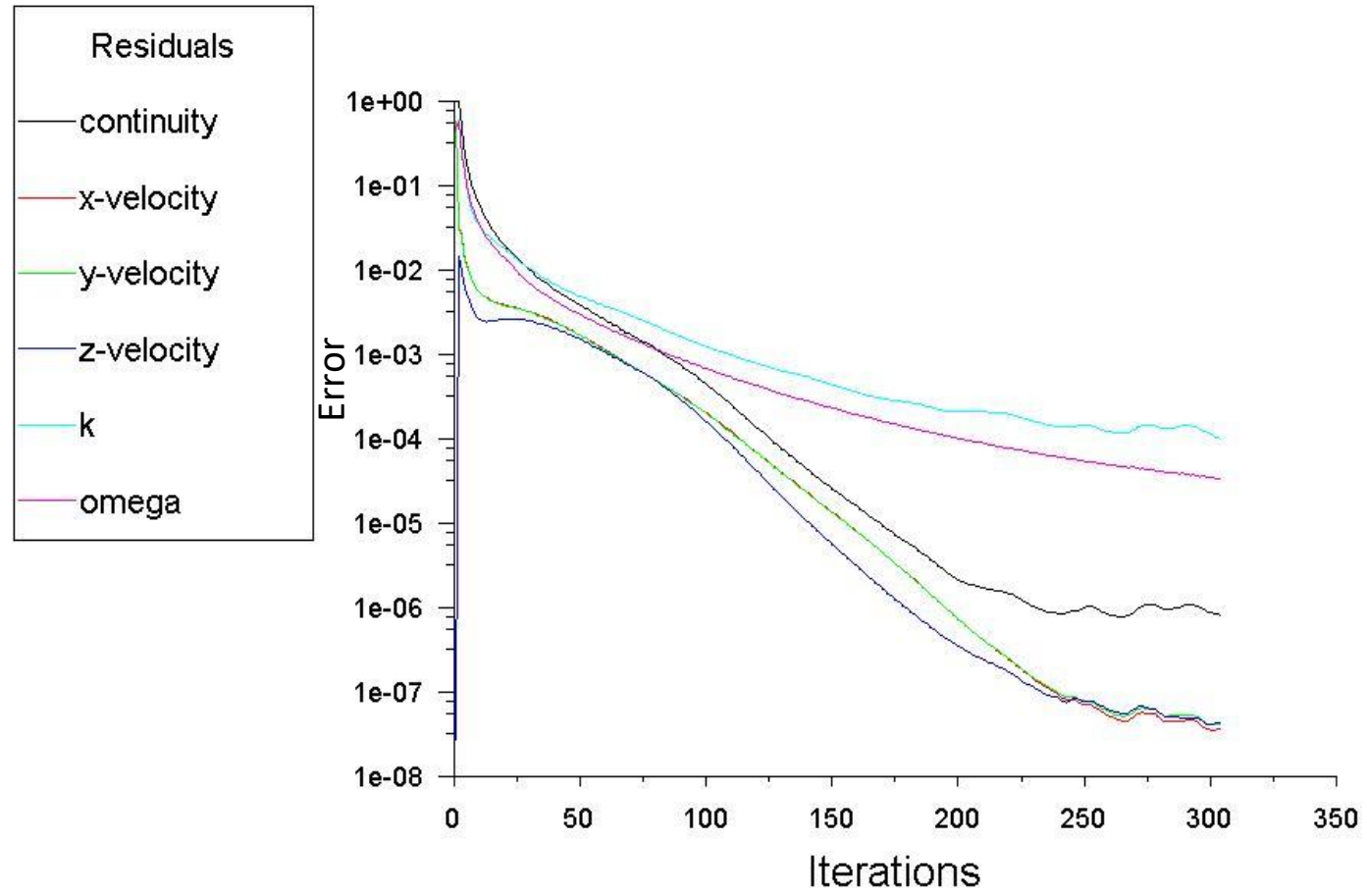

Fig. 5. Residuals for the numerical simulation of the NREL phase VI wind turbine for $\mathrm{V}=10 \mathrm{~ms}^{-1}$

The entire domain rotates at a constant RPM of 72 for all wind speeds, details of the cases are demonstrated in Table 2. For all equations, a second-order upwind special discretization is used with standard pressure. A coupled pressure-velocity coupling is also adapted with an error of $10 \mathrm{e}-4$ for all the residuals.

Table 2

NREL phase VI sequence $S$ cases

\begin{tabular}{lllll}
\hline Cases & Wind speed $\left(\mathrm{ms}^{-1}\right)$ & Density $\left(\mathrm{Kgm}^{3}\right)$ & Average rotor rotational speed $(\mathrm{rpm})$ & Pitch \\
\hline S0500000 & 5 & 1.243 & 72.1 & $3^{\circ}$ \\
S0700000 & 7 & 1.246 & 72.1 & $3^{\circ}$ \\
S1000000 & 10 & 1.246 & 72.1 & $3^{\circ}$ \\
S1300000 & 13 & 1.227 & 72.1 & $3^{\circ}$ \\
S1500000 & 15 & 1.224 & 72.1 & $3^{\circ}$ \\
S1800000 & 20 & 1.221 & 72.0 & $3^{\circ}$ \\
S2100000 & 25 & 1.220 & 72.1 & $3^{\circ}$ \\
\hline
\end{tabular}

\subsection{Turbulence Model}

Based on the accuracy of previously obtained results for wind turbine rotors CFD simulations, the Shear Stress Transport k- $\omega$ turbulence model is used to perform computation on the NREL phase VI Sequence $S$ case.

The $k-\omega$ SST model is based on the assumption that the turbulent shear stress obeys the same transport equation as the turbulent kinetic energy in an adverse pressure gradient flow. The model takes into consideration the effect of eddy viscosity. The k- $\omega$ SST is a two-equation model that supports two transport equations that describes the conditions in a turbulent flow: the first equation is kinetic energy and the second equation is dissipation rate. Eq. (1) and Eq. (2) present the k- $\omega$ SST transport equations. 


$$
\begin{aligned}
& \frac{\partial}{\partial t}(\rho k)+\frac{\partial}{\partial x_{i}}\left(\rho k V_{i}\right)=\frac{\partial}{\partial x_{j}}\left(\Gamma_{k} \frac{\partial k}{\partial x_{j}}\right)+G_{k}-Y_{k}+S_{k} \\
& \frac{\partial}{\partial t}(\rho \omega)+\frac{\partial}{\partial x_{i}}\left(\rho \omega V_{i}\right)=\frac{\partial}{\partial x_{j}}\left(\Gamma_{\omega} \frac{\partial \omega}{\partial x_{j}}\right)+G_{\omega}-Y_{\omega}+S_{\omega}
\end{aligned}
$$

where $k$ is the turbulence kinetic energy $\left(\mathrm{m}^{2} \mathrm{~s}^{-2}\right), \omega$ is the specific turbulence dissipation rate $\left(\mathrm{s}^{-1}\right), \mathrm{G}_{\omega}$ is the generation of specific dissipation rate $\left(\mathrm{kgm}^{-1} \mathrm{~s}^{-3}\right), \Gamma_{\mathrm{k}}$ and $\Gamma_{\omega}$ are the effective diffusivities $\left(\mathrm{m}^{2} \mathrm{~s}^{-1}\right)$, $Y_{k}$ and $Y_{\omega}$ are the dissipation of $k$ and $\omega\left(\mathrm{m}^{2} \mathrm{~s}^{-3}\right)$.

\section{Results}

\subsection{Low Speed Shaft Torque}

The low-speed shaft torque is obtained from the steady computations is presente in Eq. (3)

$T=n C_{T}\left(\frac{1}{2} \rho V_{\infty}^{2} S L\right)$

where, $\mathrm{T}$ is the net torque generated by the wind turbine rotor of $\mathrm{N}$ number of blades $(\mathrm{Nm}), \rho$ is the fluid density $\left(\mathrm{kgm}^{-3}\right), \mathrm{S}$ is the blade plan-form area $(\mathrm{m}), \mathrm{V}_{\infty}$ is the inflow wind velocity in an absolute frame of reference $\left(\mathrm{ms}^{-1}\right), \mathrm{L}$ is the blade span $(\mathrm{m})$ and $C_{T}$ is the torque coefficient.

The comparison of the computed low-speed torque using the k- $\omega$ SST model, plotted in Figure 6, shows that the numerical calculation can accurately predict the torque in the pre-stall region $(\mathrm{V}<10 \mathrm{~m} / \mathrm{s})$. In this region, the maximum difference is no more than 4 percent between the experimental value and the numerical results. In the post-stall region, the torque values are increasingly under-estimated. The difference between the numerical and experimental values increases from 6 percent at $13 \mathrm{~m} / \mathrm{s}$ to 15 percent at a speed of $25 \mathrm{~m} /$.

Numerically predicted torque value post-stall is less than the experimental value, it is likely due to the turbulence model failing to accurately predict flow behaviour at the deep stall region. For speeds lower than $10 \mathrm{~m} / \mathrm{s}$, where the flow is attached throughout the blade, the results of the computations are in close agreement with the experimental values. At $10 \mathrm{~m} / \mathrm{s}$, flow over half of the blade is attached and the torque value has a difference of 6 percent from the experimental values. For wind speeds larger than $10 \mathrm{~m} / \mathrm{s}$, flow separation can be observed from root to tip. In this area of the deep stall, the numerically predicted torque is less than the experimental value.

These results are consistent with the findings of Song et al., [16], who declared separation starting at a wind speed of $10 \mathrm{~m} / \mathrm{s}$ and above using an OpenFOAM PIMPLE algorithm with a stationary outer domain and rotating inner frame for a blunt edge blade profile. Additionally, a 3 percent difference is obtained compared to Aksenov et al., [17] who used a full rotor blade and structured mesh. The post-stall results follow a similar pattern to the previously mentioned numerical investigations with a consistent change. 


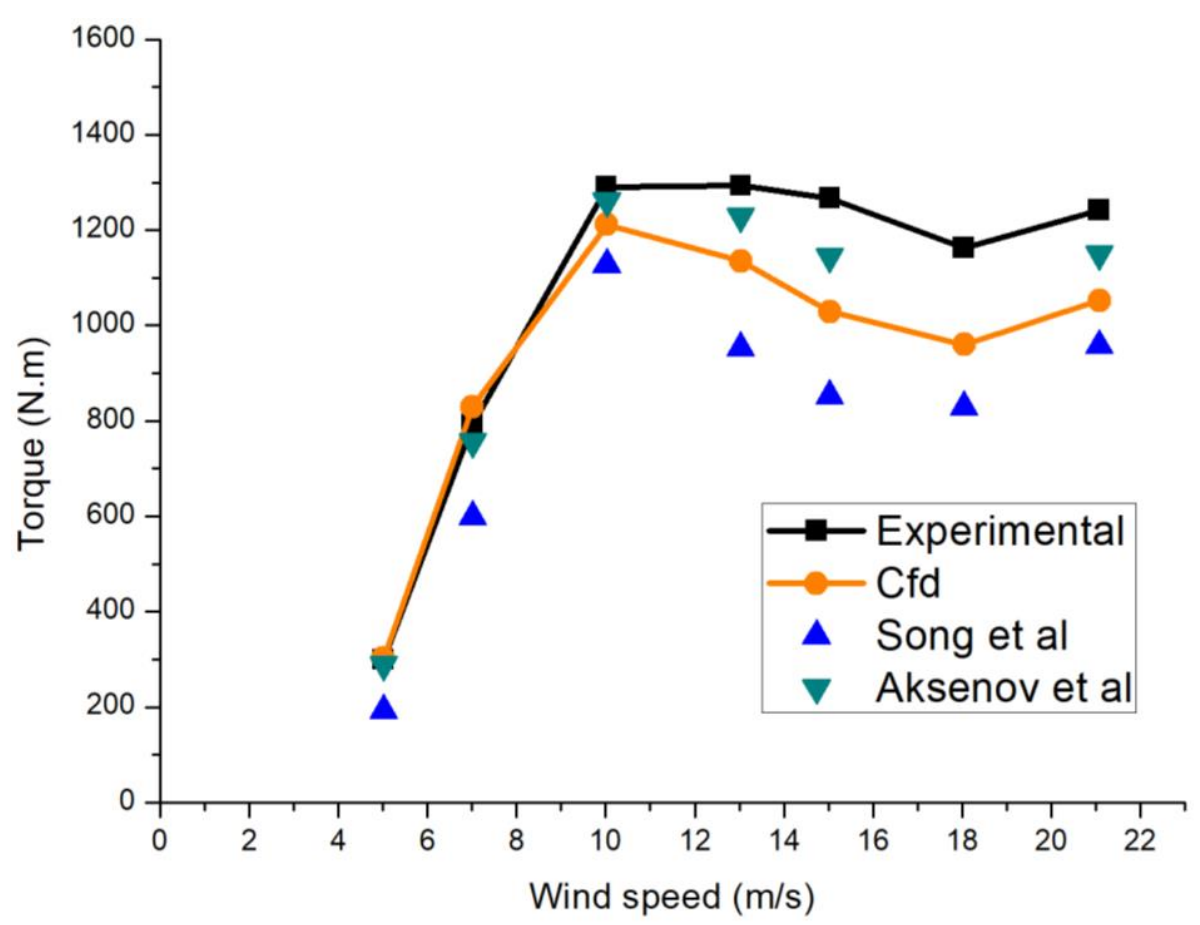

Fig. 6. comparison between experimental and numerical torque for CFD simulations conducted in this work and numerical results from Song et al., [16] and Aksenov et al., [17]

\subsection{Velocity Streamlines and Contours}

The streamlines depicted over the rotor blade surface in different wind speeds clearly demonstrate the onset of the flow separation and the size of the separation area. Prior to $10 \mathrm{~m} / \mathrm{s}$, it is clear that the blade is in the pre-stall region where the flow stays attached throughout the span of the blade as shown in Figure 7(a).

The current model predicts that separated flow over the blade will appear at $10 \mathrm{~m} / \mathrm{s}$ as illustrated in Figure 7 (b). A significant part of the blade experiences a flow separation starting at the mid-blade and extended towards the root, for all wind speeds. As we move towards the root, the speed increases locally, and the point of flow separation moves in the upstream direction towards the leading edge of the blade profile.

As the free stream velocity increases, the flow separation is observed from root to tip, leading to fully separated flow at a wind speed of $15 \mathrm{~m} / \mathrm{s}$ and higher as seen in Figure 7(c), (d), (e), and (f). Furthermore, the streamlines over the surface of the blade show that the flow within the boundary layer is three-dimensional. A span-wise velocity component is generated that leads to a fluid flow from tip to root along with the velocity component stream-wise, over the blade suction side.

A look at the volumetric velocity contours shows the progress of the separation and development of the wake area. Initially, at a speed of $7 \mathrm{~m} / \mathrm{s}$ and lower, the flow shown in Figure 8 (a) remains attached. This is in conformity with the velocity streamlines of Figure 7 (a). At a velocity of $10 \mathrm{~m} / \mathrm{s}$, where the flow is expected to separate, Figure 8 (b) shows initiation of trailing edge separation, which becomes more prominent in Figure 8 (c) at a wind speed of $13 \mathrm{~m} / \mathrm{s}$. For higher speeds, Figure 8 (d) (e) (f), illustrates that the flow is fully separated over the blade suction side and different separation regions appear. This explains the torque decrement for velocities equal to $15 \mathrm{~m} / \mathrm{s}$ and higher.

Details of the flow behaviour help assist in adapting flow control over the wind turbine blade suction side, as well as help in selecting and designing a proper flow control method. 


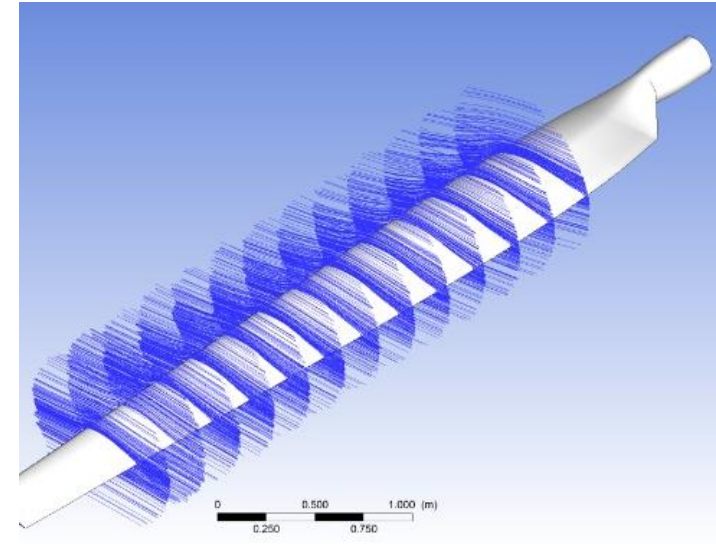

(a) $7 \mathrm{~m} / \mathrm{s}$

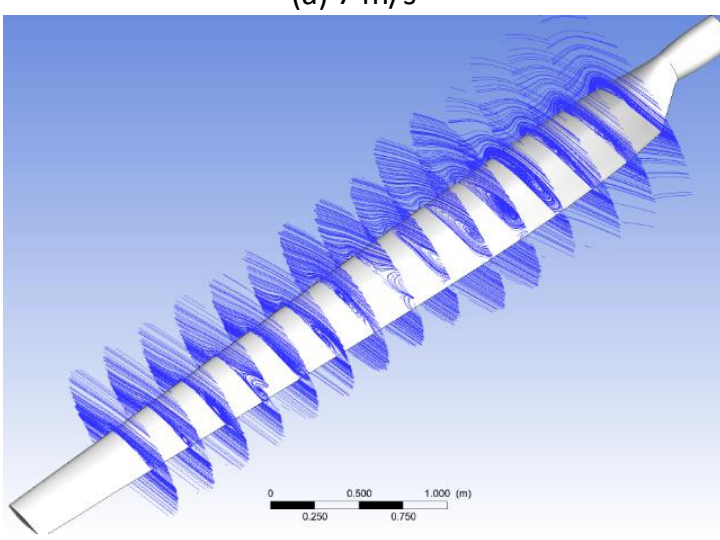

(c) $13 \mathrm{~m} / \mathrm{s}$

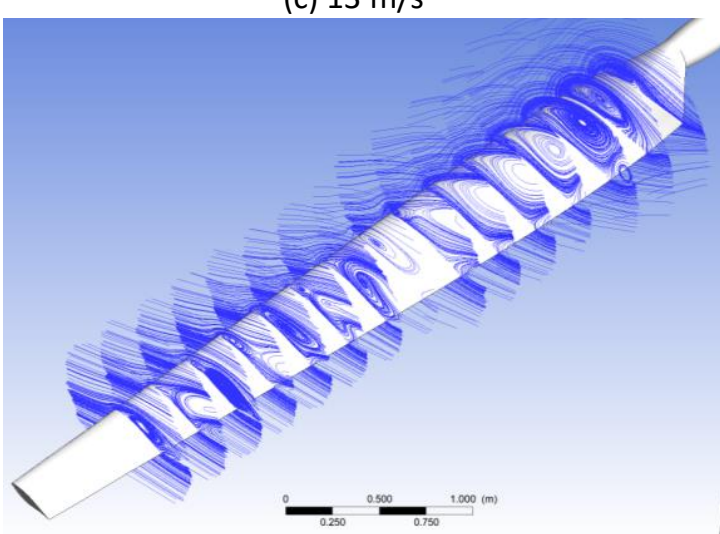

(e) $18 \mathrm{~m} / \mathrm{s}$

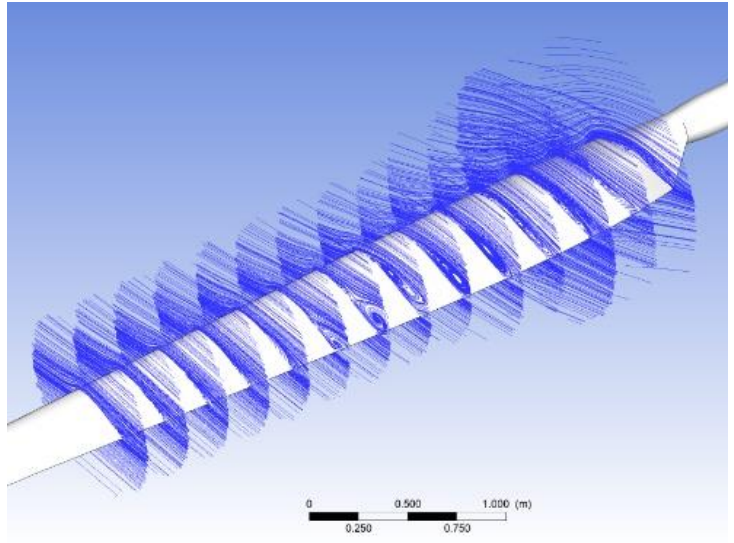

(b) $10 \mathrm{~m} / \mathrm{s}$

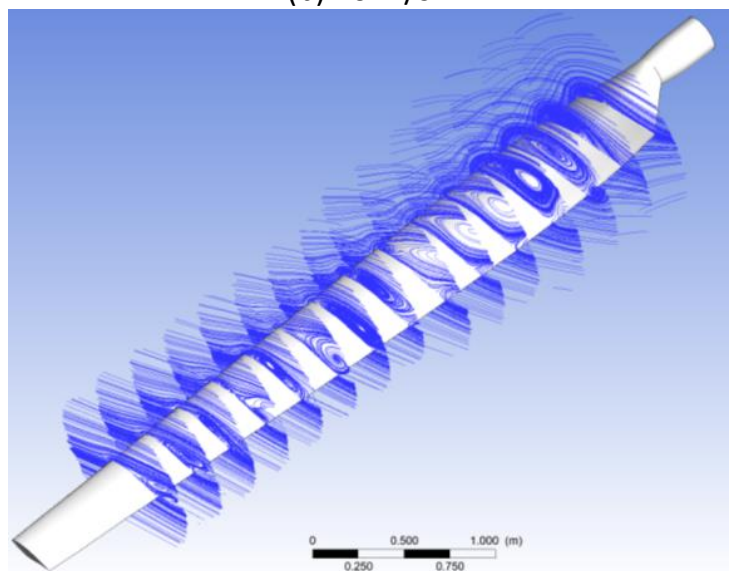

(d) $15 \mathrm{~m} / \mathrm{s}$

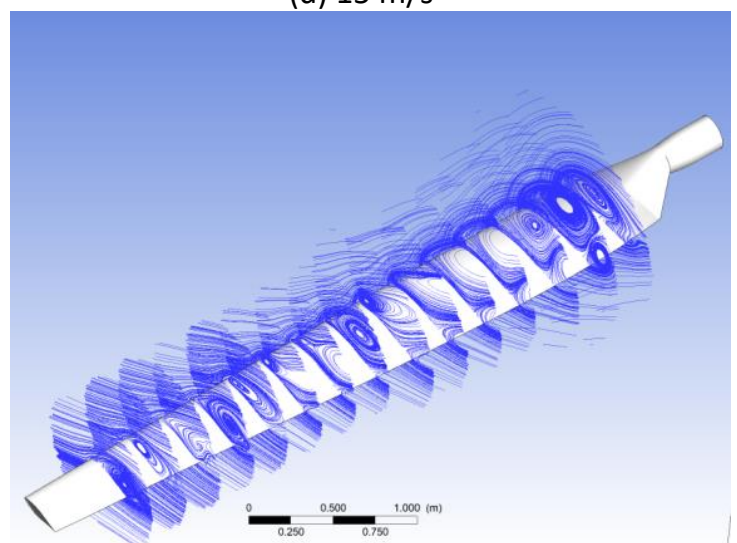

(f) $21 \mathrm{~m} / \mathrm{s}$

Fig. 7. Fluid flow streamlines over the blade span starting at $25 \%$ span line with a step of $5 \%$ for velocities from $7 \mathrm{~m} / \mathrm{s}$ to $21 \mathrm{~m} / \mathrm{s}$

The obtained aerodynamic results and flow analysis lead to a definition of the limitations and the operating range of the NREL phase VI wind turbine up to $10 \mathrm{~m} / \mathrm{s}$ for the efficient extraction of power. It is expected that as the free-stream wind speed increases, the extracted power increases as well. However, it can be observed that this wind turbine is stalled for wind speeds higher than $10 \mathrm{~m} / \mathrm{s}$. In addition to the stall phenomenon, the wake generated at this region is large and wind turbines in a wind farm are expected to function in each other's far wake. Another wind turbine operating in this wake region will produce even less energy. To benefit from higher speeds for higher power extraction, flow control techniques can be designed based on the fluid flow behavior over the base wind turbine shape. 


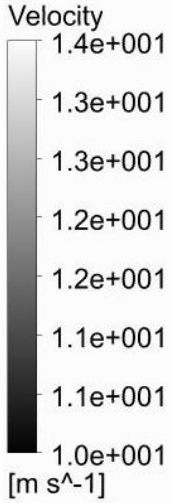

(a) $7 \mathrm{~m} / \mathrm{s}$

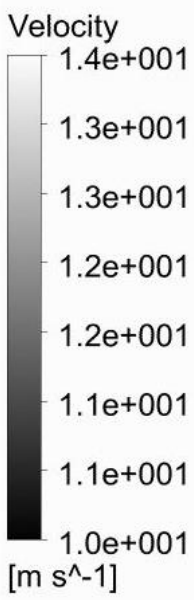

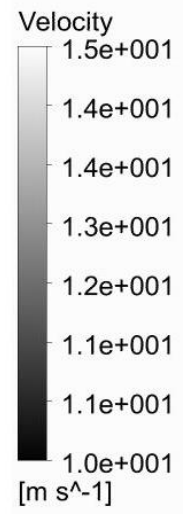

(b) $10 \mathrm{~m} / \mathrm{s}$

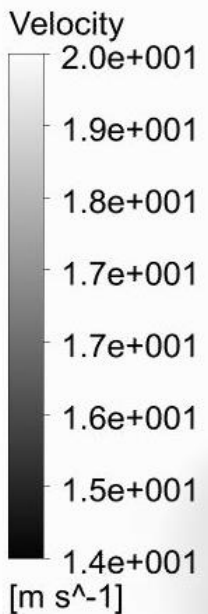

(d) $15 \mathrm{~m} / \mathrm{s}$

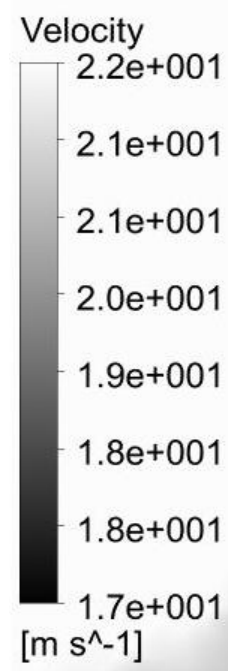

(c) $13 \mathrm{~m} / \mathrm{s}$

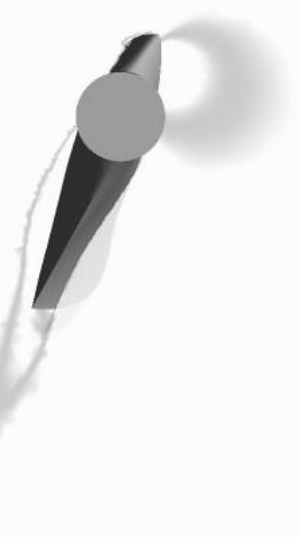

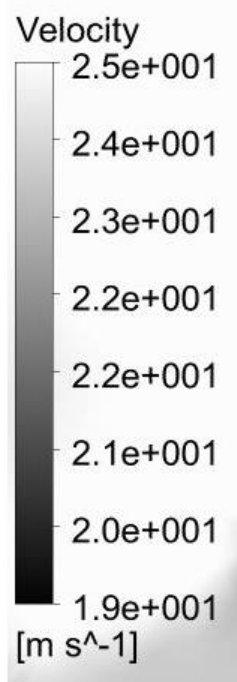

(e) $18 \mathrm{~m} / \mathrm{s}$

(f) $21 \mathrm{~m} / \mathrm{s}$

Fig. 8. Velocity contours and separation over the blade for velocities from $7 \mathrm{~m} / \mathrm{s}$ to $21 \mathrm{~m} / \mathrm{s}$ 


\section{Conclusions}

In this study, the performance of the NREL phase VI wind turbine blade is predicted numerically and compared to the experimental results. It is evident that the current model can give an accurate prediction of the flow field over a 3D wind turbine blade using a fully unstructured mesh and the k$\omega$ SST turbulence model.

The results of this study show the ability of a tetrahedral mesh and limited resources to predict the behavior of the flow over a wind turbine and the power generated. As showed before, the flow is separated at a speed of $10 \mathrm{~m} / \mathrm{s}$. In fact, the wind speeds that a wind turbine encounters in a wind farm range don't exceed $13 \mathrm{~m} / \mathrm{s}$. The wind turbine extracts the maximum energy at a velocity higher than $7 \mathrm{~m} / \mathrm{s}$. In this case, this study explores details of the flow behavior at different speeds and span locations aiming to shows the regions where flow control will be implemented in further studies.

The present work is a preliminary study and will be extended to include investigations of the effect of flow control devices over the 3D wind turbine blade with comparison to the predicted performance of the baseline blade model.

\section{Acknowledgement}

This research was not funded by any grant.

\section{References}

[1] Khattak, M. A., NS Mohd Ali, NH Zainal Abidin, N. S. Azhar, and M. H. Omar. "Common Type of Turbines in Power Plant: A Review." Journal of Advanced Research in Applied Sciences and Engineering Technology 3, no. 1 (2016): 77 100.

[2] Akhter, Md, and Farag Khalifa Omar. "Review of Flow-Control Devices for Wind-Turbine Performance Enhancement." Energies 14, no. 5 (2021): 1268. https://doi.org/10.3390/en14051268

[3] Rose, J. Bruce Ralphin, S. Ganesh Natarajan, and V. T. Gopinathan. "Biomimetic flow control techniques for aerospace applications: a comprehensive review." Reviews in Environmental Science and Bio/Technology (2021): 13. https://doi.org/10.1007/s11157-021-09583-z

[4] Simms, David, Scott Schreck, Maureen Hand, and Lee Jay Fingersh. NREL unsteady aerodynamics experiment in the NASA-Ames wind tunnel: a comparison of predictions to measurements. No. NREL/TP-500-29494. National Renewable Energy Lab., Golden, CO (US), 2001. https://doi.org/10.2172/783409

[5] Giguere, P., and Michael S. Selig. Design of a tapered and twisted blade for the NREL combined experiment rotor. No. NREL/SR-500-26173. National Renewable Energy Lab., Golden, CO (US), 1999. https://doi.org/10.2172/750919

[6] Hand, M. Maureen, D. A. Simms, L. J. Fingersh, D. W. Jager, J. R. Cotrell, S. Schreck, and S. M. Larwood. Unsteady aerodynamics experiment phase VI: wind tunnel test configurations and available data campaigns. No. NREL/TP500-29955. National Renewable Energy Lab., Golden, CO.(US), 2001. https://doi.org/10.2172/15000240

[7] Jonkman, Jason Mark. Modeling of the UAE Wind Turbine for Refinement of FAST \{_\} AD. No. NREL/TP-500-34755. National Renewable Energy Lab., Golden, CO (US), 2003. https://doi.org/10.2172/15005920

[8] Wang, Qiang, Hu Zhou, and Decheng Wan. "Numerical simulation of wind turbine blade-tower interaction." Journal of Marine Science and Application 11, no. 3 (2012): 321-327. https://doi.org/10.1007/s11804-012-1139-9

[9] Gomez-Iradi, S., R. Steijl, and G. N. Barakos. "Development and validation of a CFD technique for the aerodynamic analysis of HAWT." Journal of Solar Energy Engineering 131, no. 3 (2009). https://doi.org/10.1115/1.3139144

[10] Zahle, Frederik. "Wind turbine aerodynamics using an incompressible overset grid method." (2006). https://doi.org/10.2514/6.2007-425

[11] Hsu, Ming-Chen, and Yuri Bazilevs. "Fluid-structure interaction modeling of wind turbines: simulating the full machine." Computational Mechanics 50, no. 6 (2012): 821-833. https://doi.org/10.1007/s00466-012-0772-0

[12] Lee, Kyoungsoo, Ziaul Huque, Raghava Kommalapati, and Sang-Eul Han. "Evaluation of equivalent structural properties of NREL phase VI wind turbine blade." Renewable Energy 86 (2016): $796-818$. https://doi.org/10.1016/i.renene.2015.07.096

[13] Pape, A. Le, and J. Lecanu. "3D Navier-Stokes computations of a stall-regulated wind turbine." Wind Energy: An International Journal for Progress and Applications in Wind Power Conversion Technology 7, no. 4 (2004): 309-324. https://doi.org/10.1002/we.129

[14] Sorensen, N. N., J. A. Michelsen, and S. Schreck. "Navier-Stokes predictions of the NREL phase VI rotor in the NASA 
Ames 80-by-120 wind tunnel." In Wind Energy Symposium, vol. 7476, pp. 94-105. 2002. https://doi.org/10.2514/6.2002-31

[15] Mahu, R., F. Popescu, F. Frunzulică, and Al Dumitrache. "3D CFD modeling and simulation of NREL phase VI rotor." In AIP Conference Proceedings, vol. 1389, no. 1, pp. 1520-1523. American Institute of Physics, 2011. https://doi.org/10.1063/1.3637914

[16] Song, Yang, and J. Blair Perot. "Cfd simulation of the nrel phase vi rotor." Wind engineering 39, no. 3 (2015): $299-$ 309. https://doi.org/10.1260/0309-524X.39.3.299

[17] Aksenov, Andrey, Utkudeniz Ozturk, Cloud Yu, Petr Byvaltsev, Sinan Soganci, and Oguz Tutkun. "A validation study using nrel phase VI experiments, Part I: Low computational resource scenario." In 12 th European Conference on Turbomachinery Fluid dynamics \& Thermodynamics. EUROPEAN TURBOMACHINERY SOCIETY, 2017. https://doi.org/10.29008/ETC2017-365

[18] Chaviaropoulos, P. K., and Martin OL Hansen. "Investigating three-dimensional and rotational effects on wind turbine blades by means of a quasi-3D Navier-Stokes solver." J. Fluids Eng. 122, no. 2 (2000): $330-336$. https://doi.org/10.1115/1.483261

[19] Akbarzadeh, A. M., and I. Borazjani. "Controlling flow separation on a thick airfoil using backward traveling waves." AIAA Journal 58, no. 9 (2020): 3799-3807. https://doi.org/10.2514/1.J059428

[20] Colonius, T., and W. F. J. Olsman. "Numerical Simulation of Flow over an Airfoil with a Cavity." AIAA Journal 49 , no. 1 (2011).

[21] Davide, L., D. Raffaele, F. D. Gregorio, and G. luso. "Effects of a trapped vortex cell on a thick wing airfoil." Exp Fluids 51 (2011): 1369-1384. https://doi.org/10.1007/s00348-011-1160-9

[22] Vuddagiri, Aswin, Paresh Halder, Abdus Samad, and Abhijit Chaudhuri. "Flow analysis of airfoil having different cavities on its suction surface." Progress in Computational Fluid Dynamics, an International Journal 16, no. 2 (2016): 67-77. https://doi.org/10.1504/PCFD.2016.075151

[23] Wang, Jinjun, and Lihao Feng. Flow control techniques and applications. Cambridge University Press, 2019.

[24] Menezes, Eduardo José Novaes, Alex Maurício Araújo, and Nadège Sophie Bouchonneau da Silva. "A review on wind turbine control and its associated methods." Journal of cleaner production 174 (2018): 945-953. https://doi.org/10.1016/i.jclepro.2017.10.297

[25] Simms, Dave, Maureen Hand, Dave Jager, Jason Cotrell, Mike Robinson, Scott Schreck, Scott Larwood, and Lee Fingersh. "Wind tunnel testing of NREL's unsteady aerodynamics experiment." In 20th 2001 ASME Wind Energy Symposium, p. 35. 2013. https://doi.org/10.2514/6.2001-35

[26] Chao, D. D., and C. P. Van Dam. "Computational aerodynamic analysis of a blunt trailing-edge airfoil modification to the NREL Phase VI rotor." Wind Energy: An International Journal for Progress and Applications in Wind Power Conversion Technology 10, no. 6 (2007): 529-550. https://doi.org/10.1002/we.239

[27] Moshfeghi, Mohammad, Ya Jun Song, and Yong Hui Xie. "Effects of near-wall grid spacing on SST-K- $\omega$ model using NREL Phase VI horizontal axis wind turbine." Journal of Wind Engineering and Industrial Aerodynamics 107 (2012): 94-105. https://doi.org/10.1016/i.jweia.2012.03.032 